
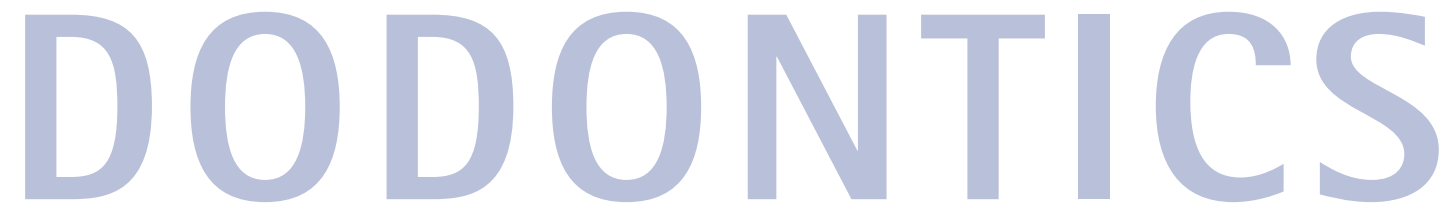

\title{
Endodontic crowns
}

\section{Precision work}

Cerana Endo Inlays seal ceramic crowns following endodontic treatment.

Manufactured from a translucent glass ceramic, they are highly resistant to fracture propagation.

According to Trycare, they are simply cemented into preformed cavities with composite and contoured and polished using diamonds.

They are supplied in a starter pack containing ten large and extra large inlays, one large and extra large preparation diamond, one ball and cone shaped diamond, curing cones and accessories.

Individual refill packs are available separately.

Reader response number 54

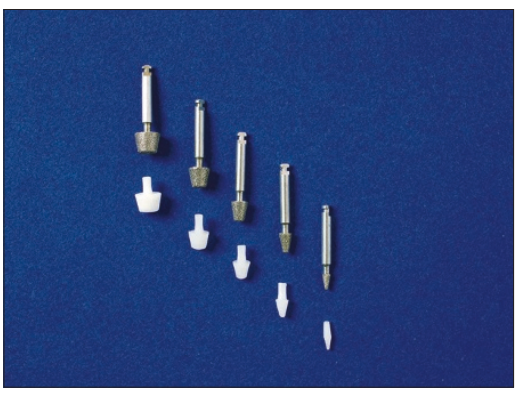

\section{Root filler}

Thermafil from Dentsply provides a three dimensional fill of the root canal. The company claims that it gives a good apical seal of the root canal including lateral canals, fills long and narrow canals and is time saving according to the company.

The product can be used for obturation of the root canal if used in conjunction with a rotary nickel titanium technique and is a tapered plastic carrier covered in alpha phase gutta-percha. It is heated with the Thermaprep plus oven, which takes 15

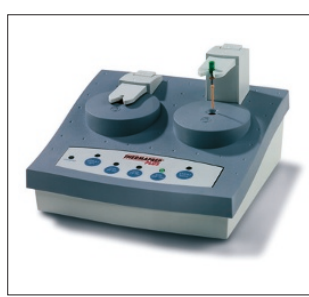
seconds to heat and place, using a small amount of force and extended working time sealer.

Reader response number 56

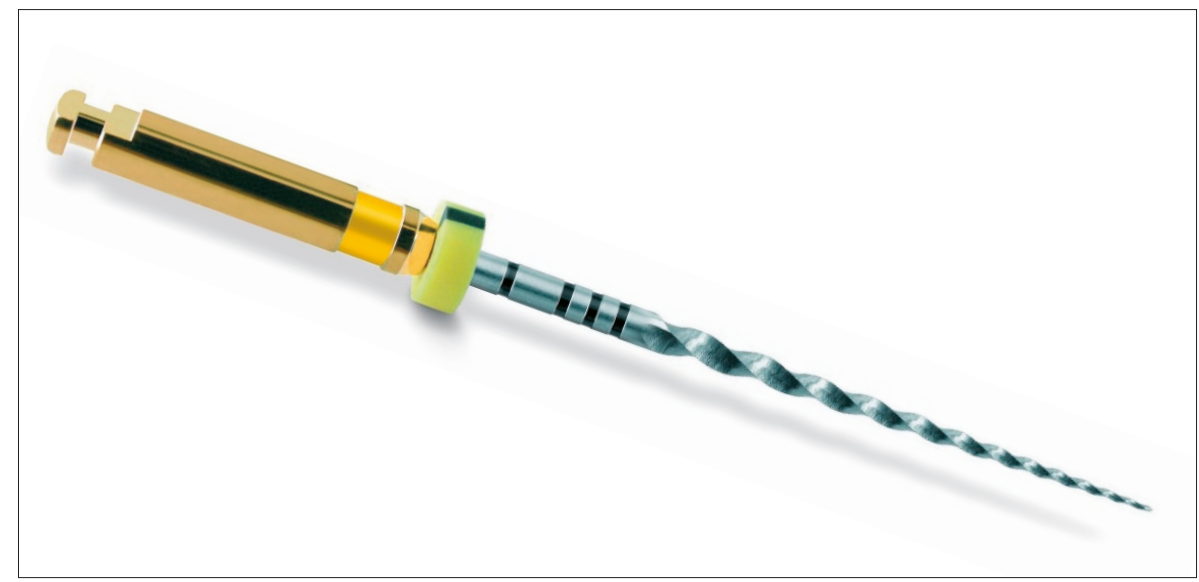

ProTaper can achieve successful canal shaping even in difficult, highly calcified and severely curved root canals, according to Dentslpy. The instrument has a convex triangular cross section which minimises the contact area between file and dentine and has been safely incorporated by bal-

\section{Fitting the bill}

Gutta-percha points from UnoDent endodontic offer a reliable alternative to premium branded products without compromising quality according to The Dental Directory.

They come in standard or colour coded packs in a range of sizes to fill all depths of cavities. The standard packs are available in sizes 10 to 140 as well as assorted ones that cover the following size range - 15-40, 4580 and 90-140.

Reader response number 57

\section{Colour coded}

Profile from Dentsply consists of three different instruments, which are recognised by rings and colours.

Profile Orifice Shapers are used in the coronal portion of the canal, Profile .06 are used in the mid portion of the canal and Profile .04 are used in the apical portion. All instruments follow ISO colour coding. Reader response number 58 ancing the pitch and helical angles.

It fits into smaller areas of dentine, minimising torsional loads, file fatigue and the potential for separation. The series consists of three shaping and three finishing instruments.

Reader response number 55
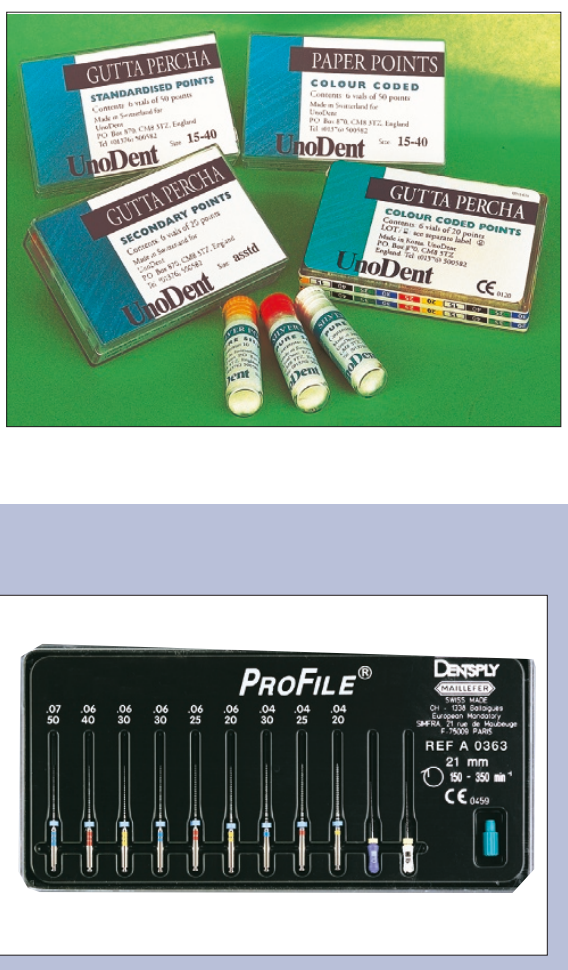


\section{Root repair}

ProRoot MTA root repair material from Dentsply is resistant to marginal leakage, allows normal healing response, sets in the presence of moisture and reduces bacterial migration. Each packet of ProRoot MTA powder comes with a pre-measured unit dose of water for convenience in mixing.

It reaches a working consistency rapidly and is ready to be applied to the prepared site. The product can be used in the repair of root perforations, apexification creating an apical plug, repair of root resorption, root end filling and pulp capping.

Reader response number 59

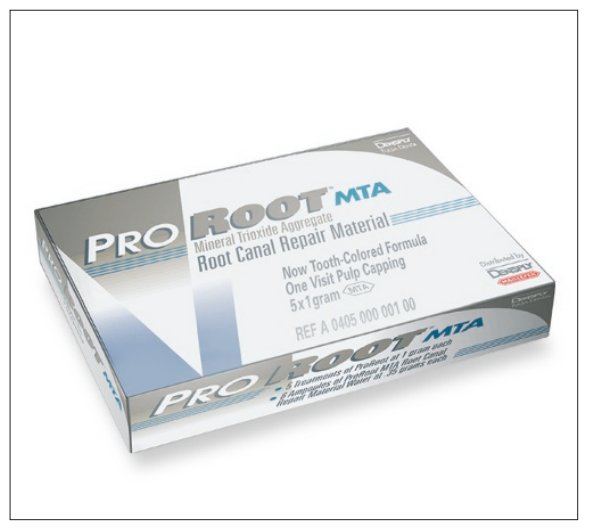

\section{Building it up}

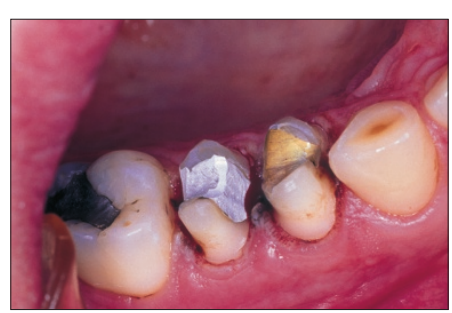

Fuji IX GP from GC (UK) Ltd can be used as a core build-up material following endodontic treatment. The product is mixed to a putty-like consistency, either by hand or by using GC's capsulated system. The non-sticky material will not pull back when placed using metal hand instruments and due to its non-slump characteristics, it will stay exactly where you place it.

It can be packed and shaped during the setting phase and the fluoride releasing material sets in four minutes and can be trimmed and finished immediately with water-cooled instruments.

As Fuji IX GP is a glass ionomer, it will adhere to any pins or posts present without the need for additional bonding agents. It exhibits high bond strengths to tooth structure and the water absorption is extremely low, as is the shrinkage.

Reader response number 60

\section{Heart of gold}

The new SIRONiTi Endodontic Handpiece from Sirona is a special-purpose handpiece for root canal treatment using nickel-titanium files.

It is equipped with a 5-step torque limiter, which can be adjusted directly via the torque preselection ring on the handpiece. For ease of use, each handpiece is supplied with a set of torque cards for the commonly available nickel-titanium file systems.

This enables the operator to see at a glance which torque setting (1-5) is appropriate for their chosen file system. The 'heart' of the SIRONiTi is a gold-plated magnetic coupling with its unique 'retrorotation' function.

If the torque limit is exceeded, the file rotation is automatically reversed preventing it from becoming jammed in the root canal.

Its ISO coupling is compatible with a wide variety of different drive systems and SIRONiTi attaches directly to the electric motor so no additional adjustments are necessary.

The product is available from Minerva Dental singly or as part of a starter kit containing a basic kit of either $25 \mathrm{~mm}$ Flexmaster, GT Rotary, ProFile or ProTaper NiTi
Files, a storage box and three plastic practice blocks.

Reader response number 61

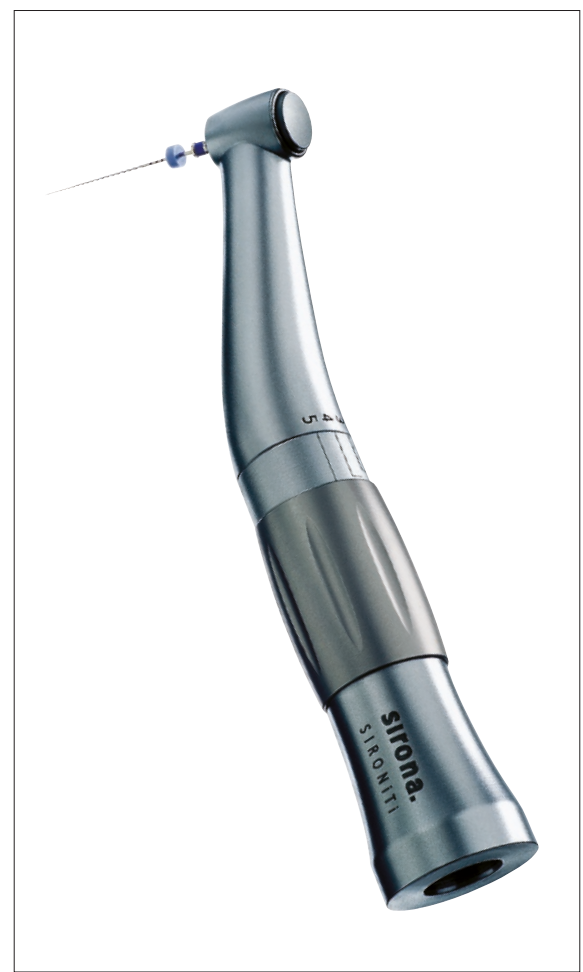

